\begin{tabular}{|c|c|}
\hline $\begin{array}{l}\text { MINING AND METALLURGY INSTITUTE BOR } \\
\text { UDK: } 622\end{array}$ & $\begin{array}{l}\text { ISSN: 2334-8836 (Štampano izdanje) } \\
\text { ISSN: 2406-1395 (Online) }\end{array}$ \\
\hline UDK: 621.9.048(045)=111 & doi:10.5937/mmeb1704123S \\
\hline
\end{tabular}

\title{
LASER BEAM DRILLING AND CUTTING OF PMMA
}

\section{Abstract}

Due to its excellent mechanical, chemical and optical properties, also on fatigue, polymethilmetacrylate (PMMA) is widely used for many purposes. PMMA has a reputation as a material that cannot be machined well, but, its elasticity and toughness enable its shaping by the deformation processes. Laser drilling and cutting are also available techniques for PMMA sheets shaping, used when both mechanical and optical PMMA properties must be preserved.

In this work, the influence of $\mathrm{CO}_{2}$ laser cutting/drilling on transparent and coloured PMMA surfaces is investigated, as well as by the other laser systems. The cut surfaces were investigated by a light microscopy and, on those surfaces, the average surface roughness $R_{a}$ was measured. The material zone affectted by the laser beam during the cutting process was monitored by a thermal imaging, and theoretical simulations of temperature distribution in this area were performed using the various versions of COMSOL packages.

Keywords: PMMA, laser cutting/drilling, surface roughness, thermal imaging, temperature distribution calculations

\section{INTRODUCTION}

Thanks to its excellent corrosion resistance, relatively good mechanical properties and low friction PMMA is used as a construction material in many applications, like for vehicle (automobile) and airplane windows, as a component of holographic and similar optical materials, matrix for contemporary magnetic materials, in furniture, toys and commercial boards.

Concerning the broad area of its applications, the vast of reference data can be found about the laser methods for PMMA shaping [1-14]. The optimization of laser systems working regimes, including the investigated of large variety of laser pulses going down to femtosecond duration were also performed, both theoretically and experimentally.

The plasma state was produced in PMMA using the UV laser, and interesting chemical processes were observed. It is also worth to underline simulation of different processes when various types of laser systems were used simultaneously, including some unconventional measuring methods [6-17].

Thermal imaging. Thermal imaging is a suitable method for in-situ monitoring of the laser - material interaction, which in addition enables a comparison of different simulation models. Thermal imaging cameras enable a full image observation of a desired area, inspection of a system under load, identification and location the problems accompanying the heat production (hot points) and prevention the related da-

\footnotetext{
* Faculty of Electrical Engineering, University of Belgrade, Serbia

** Technical College Novi Beograd, Serbia

**** Metalac A.D., Gornji Milanovac (milovjani@gmail.com)

${ }^{* * * * *}$ Technical Faculty, University of Belgrade, Bor
} 
mages, temperature measurements and data storage, allowing a considerable economization of time and resources [15-16] during the laser-material interaction.

In this paper, the thermal imaging is applied for visualization and quantitative data acquisition during the laser drilling/ cutting of PMMA.

Roughness. Roughness is one of the universal surface characteristics and a good indicator of material mechanical performance. No matter the method of processing (turning, milling, grinding, sand blasting, cutting, ...) the surface irregularities of machined components may initiate the nucleation sites for cracks, corrosion and other damages, even after polishing, so one of the goals of the laser processing is to minimize the surface roughness. Strictly speaking, dust particles and other conta-mination are not considered as the surface roughness, because they can be relatively easy removed from the surface.

Mechanical and optical (including laser) profilers are in use for measuring the roughness profiles. The surface roughness was measured by a roughness comparator with a diamond stylus in our experiments. The surface roughness is usually characterized by two main attributes: roughness ampli-tude, as a measure of height, or depth, and roughness sampling length, as a measure of frequency of roughness pattern appearing.

Optical properties, including the wellknown numbers ( $\mathrm{Re}, \mathrm{Nu}, \mathrm{Pr}$ ) from fluids dynamics have an important role for characterization the laser processing of PMMA [17-23]. Some other advanced surface treatments, like high frequency (HF) induction, and electron-beam irradiation are in competitions with laser processing of PMMA, es pecially for its applications as chamber or windows material.

\section{EXPERIMENTAL}

Laser parameters, used during the $\mathrm{CO}_{2}$ $(\lambda=10.6 \mu \mathrm{m})$ processing of PMMA, were: laser power $\approx 80 \mathrm{~W}$, pulse duration $0.7 \mathrm{~ms}$. The PMMA absorption coefficient was assumed to be $4 \%$. Numerical simulations using these parameters were performed using the Comsol Multiphysics 3.5, 4.4 and 5.2. program packages $[13,14]$.

\subsection{Samples}

The samples, used for the presented investigations, were taken from large PMMA plates, and their images are presen-ted in Fig. 1 (a-d). White samples $\mathrm{C} 1 \div \mathrm{C} 4$ have dimensions $48.1 \times 96.6 \times 3 \mathrm{~mm}$, while black samples are $21.4 \times 64.8 \times 9.3 \mathrm{~mm}$.

\subsection{Cutting}

Cutting of the PMMA samples was performed by a $\mathrm{CO}_{2}$ laser with characteristics stated above, under a cutting speed of $\approx 40 \mathrm{~cm} / \mathrm{min}$. During these experiments, the oscillations in power supply were registered with a slight influence on the cut surface roughness.

\section{RESULTS AND DISCUSSIONS}

\subsection{Roughness Measurements}

Surface roughness can be numerically characterized by maximal height (depth) $\mathrm{R}_{\max }$ of the roughness pattern, and its arithmetic average value $R_{a}$. In the presented investigations, $R_{a}$ measurements were performed by a mechanical method using a diamond stylus. Sketch of black specimens and its roughness values are shown in Fig. 2. 

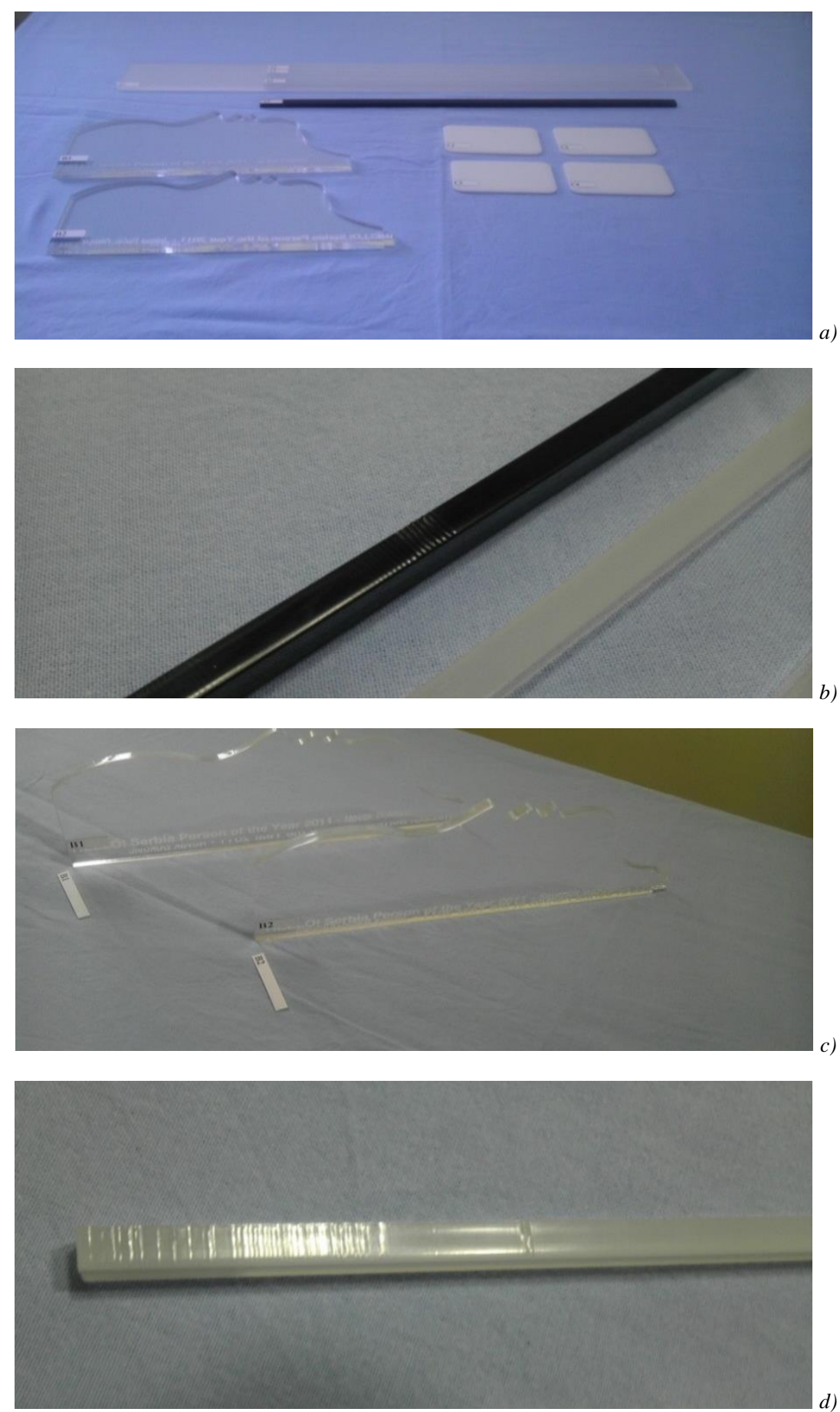

Fig. 1 PMMA samples obtained by $\mathrm{CO}_{2}$ laser cutting 


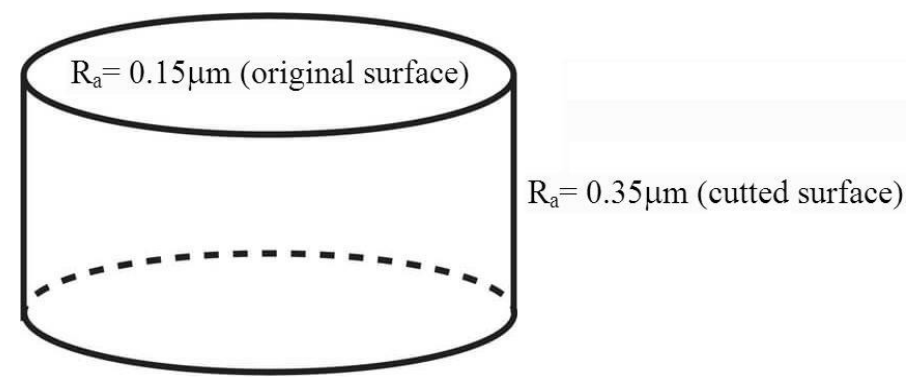

Fig. 2 Sketch of black PMMA specimen with $R_{a}$ values of appropriate surfaces

Some measured roughness values of sam- $\quad$ ples presented in Fig.1 are given in Table 1.

Table 1 Roughness $R_{a}$ of specimens cut by a $\mathrm{CO}_{2}$ laser under the speed of $40 \mathrm{~cm} / \mathrm{min}$

\begin{tabular}{|l|l|l|l|}
\hline $\mathbf{N}^{\mathbf{0}}$ & \multicolumn{2}{|c|}{ Samples } & \multicolumn{1}{c|}{$\mathbf{R}_{\mathbf{a}} \boldsymbol{\mu m}$} \\
\hline 1. & \multirow{4}{*}{ White samples } & $\mathrm{C} 1$ & 0.48 \\
\cline { 4 - 4 } & & $\mathrm{C} 2$ & 0.3 \\
\cline { 4 - 4 } & & $\mathrm{C} 3$ & 0.52 \\
\hline 3 & & $\mathrm{C} 4$ & 0.43 \\
\hline 4 & & $\mathrm{~A} 1$ & 0.062 \\
\hline 5 & & cutting I & $0.098(0.02)$ \\
\hline 6 & \multirow{3}{*}{ Cutting modification } & cutting II & 0.12 \\
\hline 7 & & & $0,35(0.015)$ \\
\hline 8 & Black specimen & & \\
\hline
\end{tabular}

\subsection{Microscopic Evaluations of \\ Laser-Cut Surfaces}

Damages and other surface changes induced in PMMA by the laser cutting/drilling are analyzed using a light microscopy, and results are presented in Fig. 3. Two characteristic areas with laser induced damages can be noticed in the presented micrographs: a) basic material far away from the laser-affected zone (LAZ) area, Fig. 3a) and laser-cut edges, Fig. 3b-g) and b).

\subsection{Thermal Imaging}

The thermal images of black and semitransparent specimens (different fillers provides different material colors) obtained du- ring the $\mathrm{CO}_{2}$ laser $(80 \mathrm{~W}, \lambda=10.6 \mu \mathrm{m}$, cutting speed $40 \mathrm{~cm} / \mathrm{min}$ ) cutting of PMMA by an IR camera (IK 21 from Vohler, Germany with professional version of the IR Snap View software package from Infrared Solutions Inc.), and in that way obtained temperature distribution are shown in Figs. 4 and 5, respectively. Before measurements were provided, the emissivity in an IR part of electromagnetic spectra firstly is determined: $\varepsilon=0.95$ for black and $\varepsilon=0.93$ for transparent PMMA specimens. The maximum temperature registered on a black PMMA specimen surface during the laser cutting was $318.4^{\circ} \mathrm{C}$. 


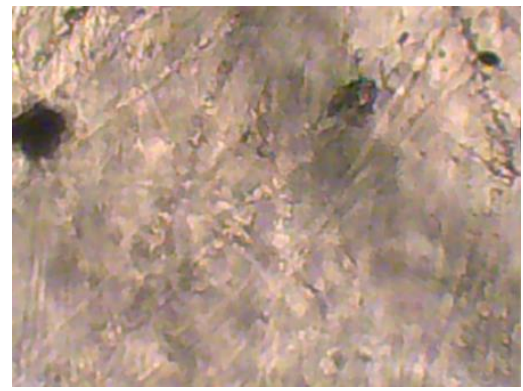

a) Micrograph of sample by a light microscope Sample surface - basic material, x20 (Microscope Litz, MZ6)

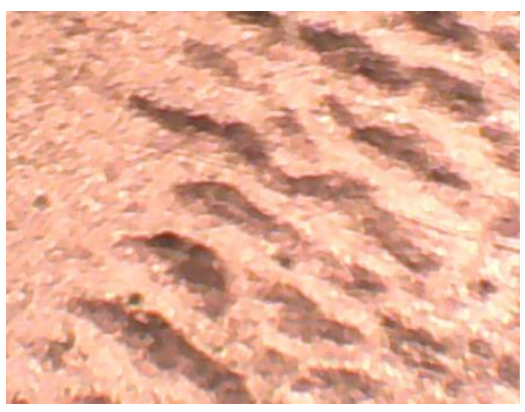

c) $x 100$

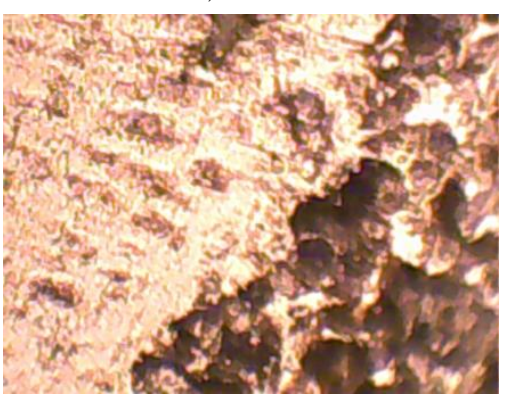

e) $x 100$

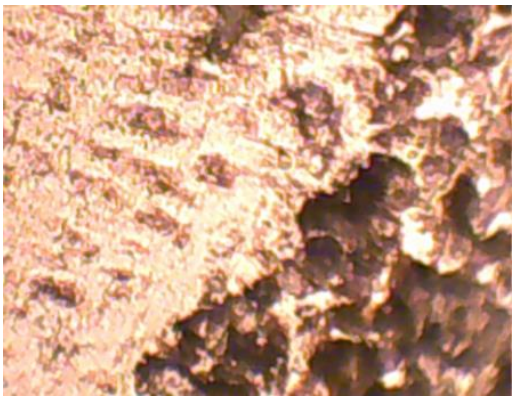

b) $X 100$

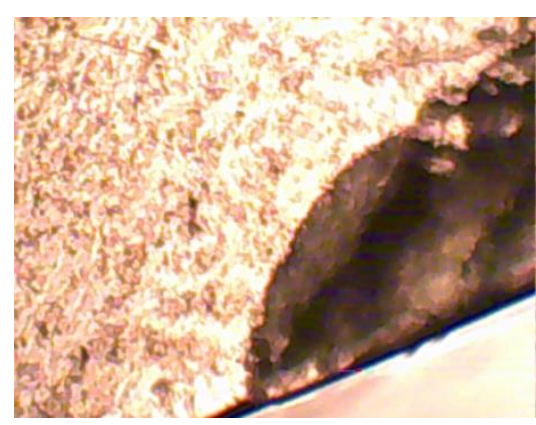

d) $x 100$

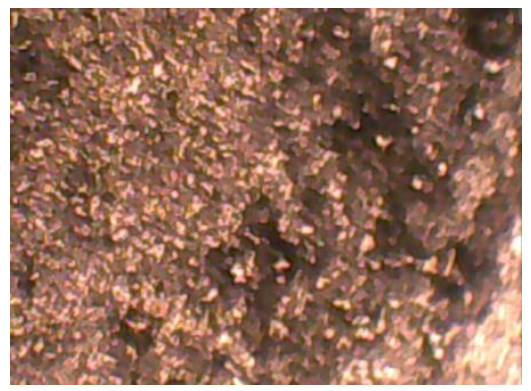

f) $x 100$

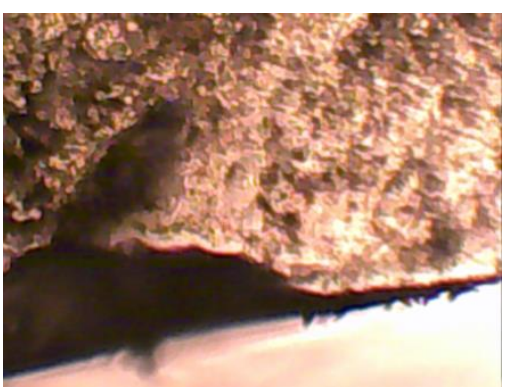

g) $x 100$

Fig 3 (a-h) Light microscope micrographs of PMMA microstructures at: a) intristic material and b-g) laser cutting zone 

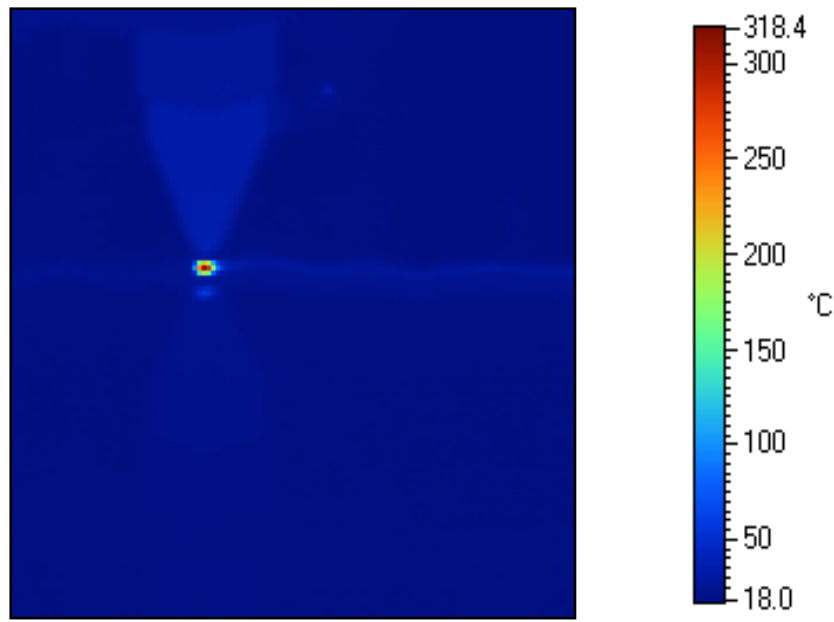

Fig. 4 Thermal image of $\mathrm{CO}_{2}$ laser cutting obtained on a cut black PMMA sample, together with temperature distribution scale

The maximum temperature reached on sample during the $\mathrm{CO}_{2}$ laser cutting was the surface of a semitransparent PMMA $243.5^{\circ} \mathrm{C}$, Fig.5.

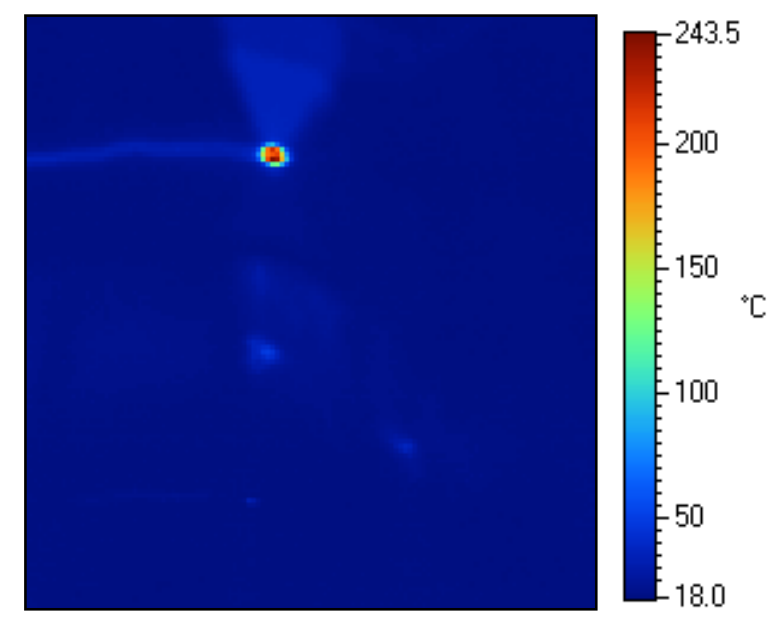

Fig. 5 Thermal image a $\mathrm{CO}_{2}$ laser cutting obtained during the cutting of a semitransparent PMMA sample, together with a temperature distribution scale

\section{SIMULATION OF TEMPERATURE DISTRIBUTION DURING LASER CUTTING OF PMMA}

Modeling the interaction of laser beam with material is performed using the COMSOL Multiphysics packages (versions

3.5, 4.4 and 5.2). Therefore, the temperature distribution, as a consequence of absorbed energy from laser beam into material and 
other heat processes generated into the material are analyzed. In this case, only the solid state is considered, in applying the corresponding mode for heat conduction.

\subsection{Thermodynamics Simulations of Heat Distribution}

The heat conduction is modeled by the equation:

$$
\delta_{t s} \rho C_{p} \frac{\partial T}{\partial t}-\nabla(k \nabla T)=Q
$$

where:

$\delta_{\mathrm{ts}}$ - time scalar coefficient,

$\rho$ - specific density,

$C_{p}$ - heat capacity at constant pressure,

$\mathrm{k}$ - (in general) tensor of heat conductivity, and

$Q$ - total heat source or sink.

If it is needed, the model can include the transverse heat convection, and surface (2D) radiation, by incorporation of the two new terms in eq. (1):

$\delta_{t s} \rho C_{p} \frac{\partial T}{\partial t}-\nabla(k \nabla T)=Q+\frac{h_{\text {trans }}}{d A}\left(T_{\text {ext }}-T\right)+\frac{C_{\text {trans }}}{d A}\left(T_{\text {ambtrans }}^{4}-T^{4}\right)$

Those new terms describe the heat energy delivered from the affected area to the environment by transverse connective, and out-of plane radiation cooling.

Described model is applicable if there is no phase transition, and other substantial surface changes, i.e. for temperatures profiles below the melting point. Such a simulation is useful for understanding the processes further from the laser interaction area, and (or) during the later stages of material cooling. Such approach is applicable in cases when blowing appears during laser processing.

\subsection{Simulations using COMSOL Mul- tiphysics Program Packages}

Simulations of thermal distribution in PMMA during $\mathrm{CO}_{2}$ and $\mathrm{Nd}^{3+}$ :YAG laser cutting/drilling/ engraving/thermal surface treating were done using three program packages COMSOL Multiphysics, versions 3.5, 4.4 and 5.2. For $\mathrm{Nd}^{3+}$ :YAG is performed simulation for one case using Comsol 3.5. absorbed until to $1 \mathrm{~mm}$ in depth in material. For such data, the calculated maximum temperature was $430 \mathrm{~K}\left(159^{\circ} \mathrm{C}\right)$, slightly below the melting point $(433 \mathrm{~K})$, softening point $110+273=383 \mathrm{~K}$, melting range $(82 \div 95)+273=355 \div 368 \mathrm{~K}[21-24]$.
Using the program package COMSOL Multiphysics 4.4 , the temperature distribution in PMMA sample after $\mathrm{CO}_{2}$ laser beam action during cutting is simulated. The temperature distribution in 2D space at momentum of $1 \mathrm{~s}$ after starting the operation is given in Fig. 6. Absorption coefficient is assumed to be $100 \%$. CW laser beam of $80 \mathrm{~W}$ mean power, and diameter of spot of $2 \mathrm{~cm}$ were parameters for simulation. Next data about PMMA were incorporated in this calculation: thermal conductivity $\lambda=18 \mathrm{~W} / \mathrm{mK}$, density $\rho=1190 \mathrm{~kg} / \mathrm{m}^{3}$ and specific heat $\mathrm{C}_{\mathrm{p}}=1450 \mathrm{~J} / \mathrm{kgK}$. The $\mathrm{cw} \mathrm{CO}_{2}$ laser beam with previously stated parameters and spot diameter of $2 \mathrm{~cm}$ were considered in simulation under the assumption that the energy of laser beam is completely absorbed along the first $1 \mathrm{~mm}$ from the material surface. The 2D temperature distribution at $1 \mathrm{~s}$ after the start of the laser interaction is presented in Fig. 6. For such data the calculated maximum temperature was $430 \mathrm{~K}$ $\left(159^{\circ} \mathrm{C}\right)$, slightly below melting point (433K).

Diameter of $2 \mathrm{~cm}$ is pretty large for cutting in the applied working conditions, but it could be of interest for the local thermal treatments of particular surfaces using an adequate beam expander. The value of absorption coefficient deserves a special discussion. 


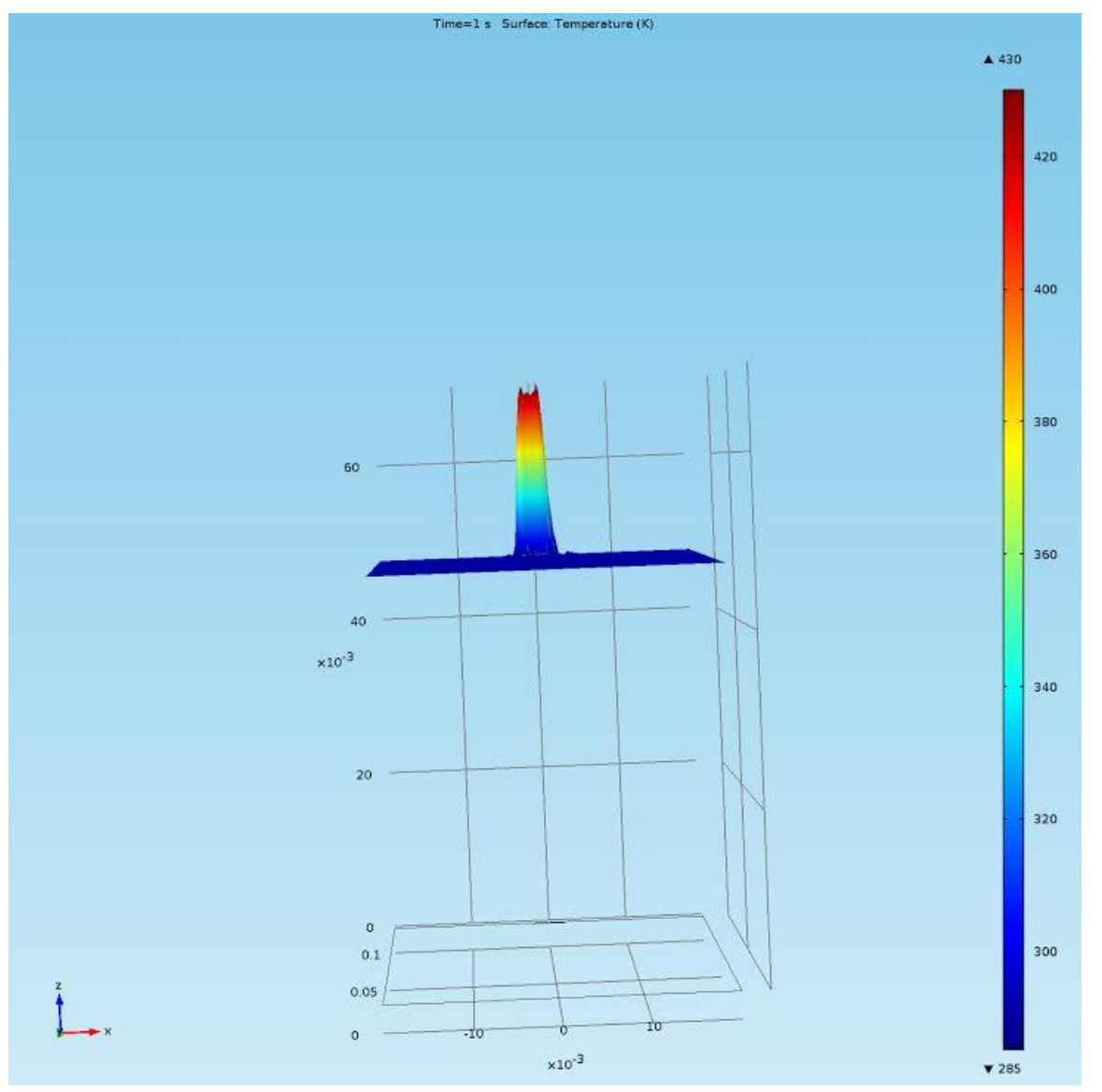

Fig. $62 D$ temperature profile obtained by simulation with COMSOL Multiphysics 4.4 program package and parameters started in the text $1 \mathrm{~s}$ after start of the $\mathrm{cw} \mathrm{CO}_{2}$ laser beam-PMMA

This simulation might be in relation on engraving process for specimens thicker than $1 \mathrm{~mm}$, when greater spot surface is available, so this approach could be applied for engraving by the wider lines.

\subsubsection{Temperature Simulations by COMSOL}

Multiphysics Package 4.4 Version.

More Realistic Conditions for

Simulations of Cutting Processes

The simulation under same thermodynamic conditions further is provided after $1.5 \mathrm{~s}$ from the starting of operation, Fig. 7. The 3D profile of temperature distribution after $1.5 \mathrm{~s}$ is shown in Fig. 7a), while the 2D profile in Fig. 7b). The time is considered to be from the beginning of interaction, under the same other working parameters.

Cutting speed, data about material properties, material thickness, etc., are however data which are necessary to know, but for fast simulation as here the phase transitions were not included. Appearance of phase transitions in plastic materials need more detailed approach, knowing for example the Verdet constant, laser number etc. $[17,18]$.

Described model is applied in the case without phase transition and without change of surface. In other words, it can be used for temperatures profiles below the melting point. 

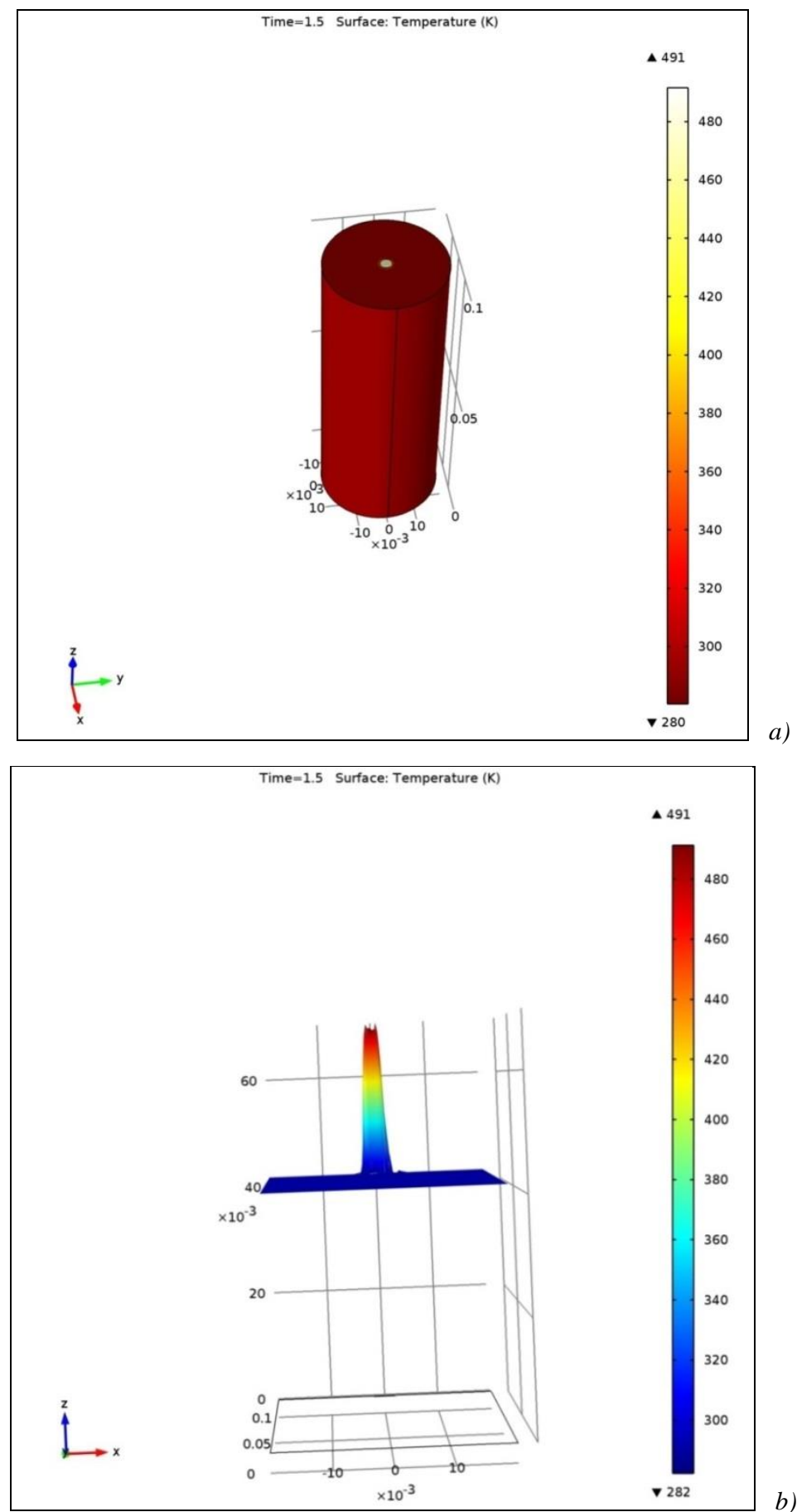

Fig. 7 Temperature distribution $1.5 \mathrm{~s}$ after the start of the $\mathrm{cw} \mathrm{CO}_{2}$ laser beam - PMMA interaction obtained by simulation using the COMSOL Multiphysics 4.4 Program Package: a) $3 D$ distribution, and b) 2D distribution. Simulation parameters are the same as in Fig. 6 
4.2.2 Temperature Simulations of $\mathrm{CO}_{2}$ and Nd3+: YAG Laser-PMMA Interaction by COMSOL Multiphysics 3.5

Program Package

Simulation of the temperature distribution during the laser cutting of PMMA is performed by COMSOL Multiphysics 3.5 Program Package and extended to two laser beams, cw- $\mathrm{CO}_{2}$ and pulse $\mathrm{Nd}^{3+}$ : YAG.
$\underline{T h e} \mathrm{cw}-\mathrm{CO}_{2} \underline{\text { laser - PMMA interac- }}$ tion.

The penetration depth of the laser beam of $0.2 \mathrm{~mm}$ was used during the simulation, with all other working parameters being the same as in Fig.6. Under those conditions the maximum temperature of $775.1 \mathrm{~K}\left(502^{\circ} \mathrm{C}\right)$, was obtained, Fig. 8.

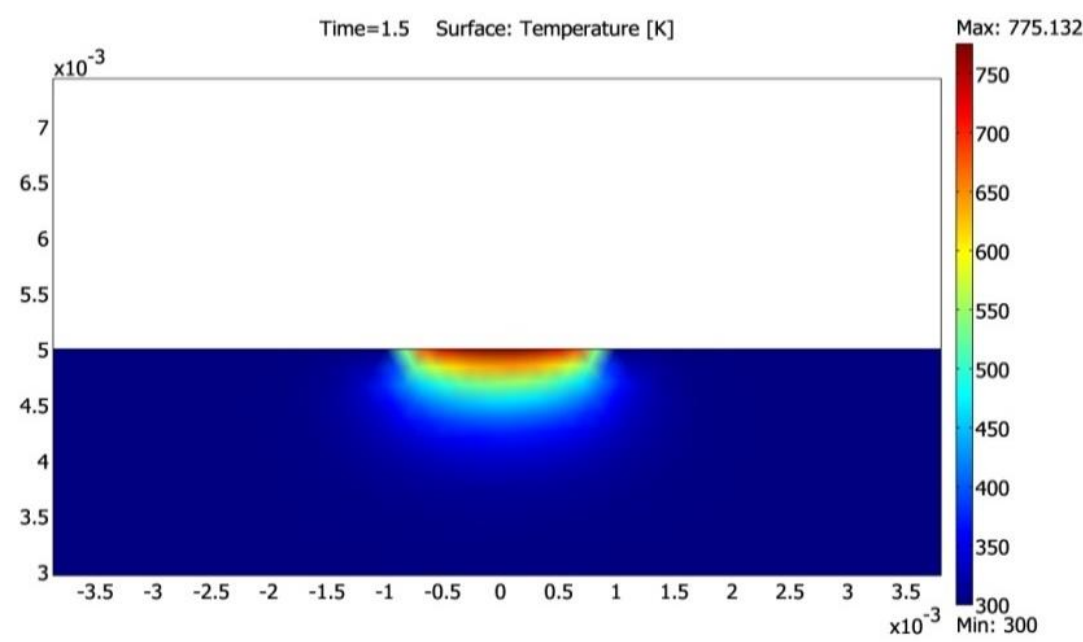

Fig. 8 Temperature distribution during the $\mathrm{cw}-\mathrm{CO}_{2}$ laser-PMMA interaction $1.5 \mathrm{~s}$ after its start for laser beam penetration depth of $0.2 \mathrm{~mm}$, simulated by COMSOL Multiphysics 3.5 Program Package

The $\mathrm{Nd}^{3+}$ :YAG laser - PMMA interaction.

The temperature distribution during t $\mathrm{Nd}^{3+}$ :YAG $(\lambda=1.06 \mu \mathrm{m}$, mean power $5 \mathrm{~kW}$ ) laser - MMA interaction has been simulated, as well. In this case the PMMA absorption coefficient of $4 \%$, and a uniform energy distribution over the laser beam cross section were assumed. Under these conditions, the maximum obtained temperature is $879.7 \mathrm{~K}$, as it could be seen in Fig. 9, indicating that a model, which includes the phase transition and the latent heat must be used. However, the presented model can give some answers about the conditions around the interaction threshold.

\subsubsection{Temperature Distribution Simulations of the $\mathrm{CO}_{2}$ laser - PMMA Interaction by COMSOL Multiphysics 5.2 Program Package}

The temperature distribution during the $\mathrm{CO}_{2}$ laser - PMMA interaction is analyzed in more details using the simulations performed by the COMSOL Multiphysics 5.2 Program Package. 


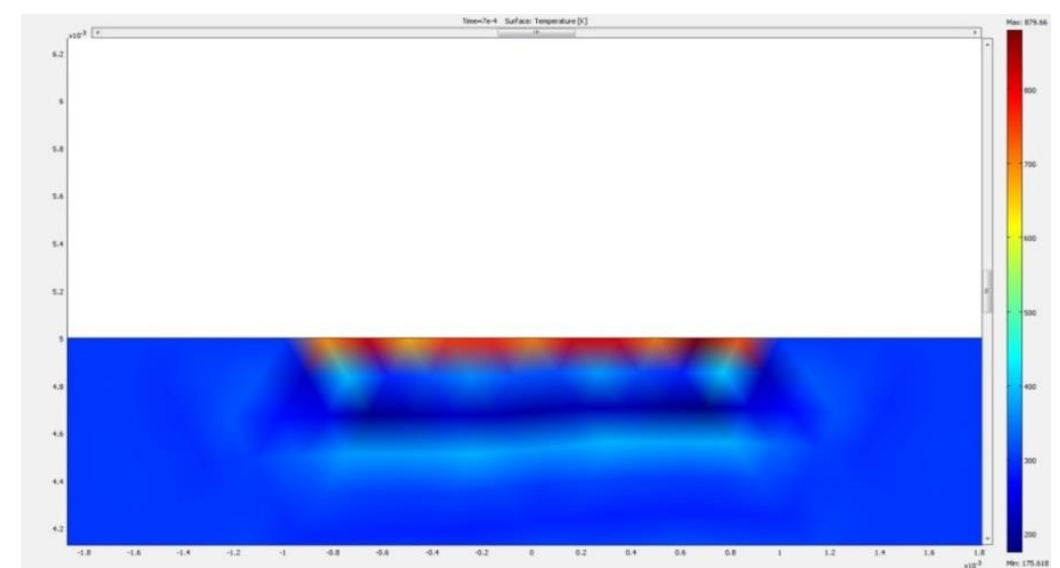

Fig. 9 Temperature distribution in PMMA after $0.7 \mathrm{~ms}$ of the $\mathrm{Nd}^{3+}: Y A G$ laser pulse duration, obtained by the COMSOL Multiphysics 3.5 Program Package simulations

The simulation parameters were the same as previously stated, with a cutting speed of $40 \mathrm{~cm} / \mathrm{min}(6.67 \mathrm{~mm} / \mathrm{s})$, and sample size of $1 \times 1 \times 1 \mathrm{~cm}$. The laser beam profile was treated as the Gaussian with the standard deviation of $2 \mathrm{~mm}$. The laser beam entering point was set at $\mathrm{O}=(0.005,0.005$, 0.02 ), and beam orientation is defined with vector $\mathrm{e}=(0,0,-1)$.

The Gaussian distribution is given by a function of:

$$
f=\frac{1}{2 \pi \sigma^{2}} \exp \left(-\frac{d^{2}}{2 \sigma^{2}}\right)
$$

where $d$ is:

$$
d=\frac{\|e \times(x-0)\|}{\|e\|}
$$

The temperature distribution $0.3 \mathrm{~s}$ after the start of interaction is presented in Fig. 10 a), and b). The simulations provided that under these conditions the maximum temperature reaches $3850 \mathrm{~K}$.

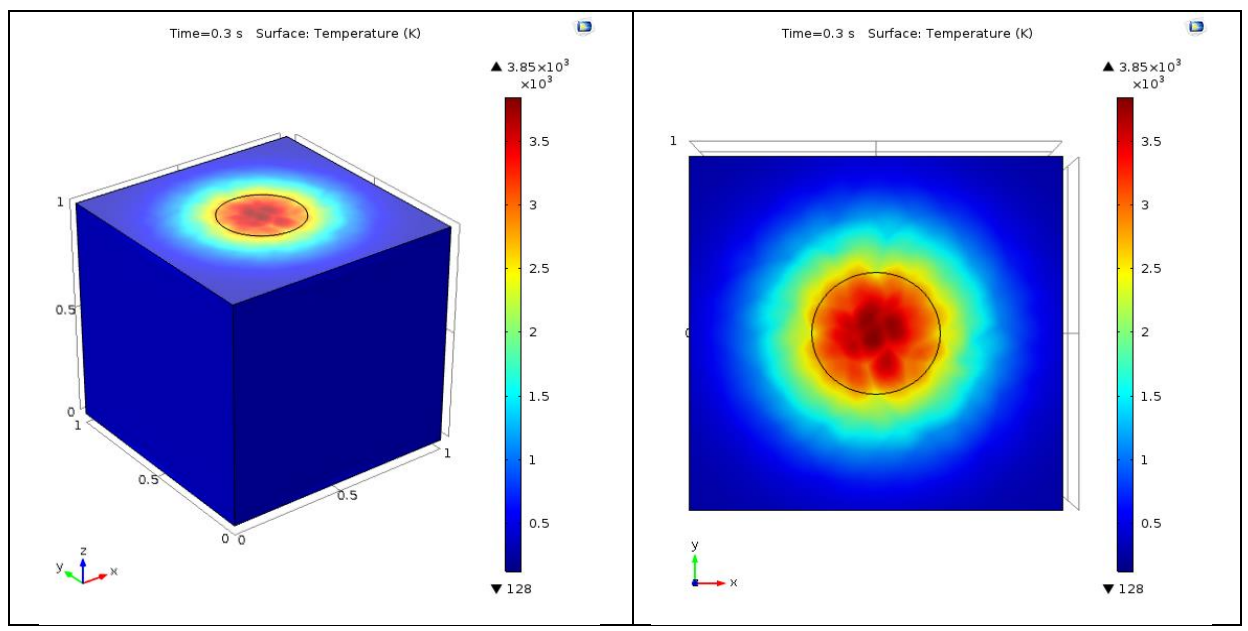

Fig. 10 Temperature distribution $0.3 \mathrm{~s}$ after the start of the $\mathrm{cw}-\mathrm{CO}_{2}$ laser - PMMA interaction simulated by the COMSOL Multiphysics 5.2 Program Package under the same working conditions as in Figs. 6-8, and the laser beam profile standard deviation of $2 \mathrm{~mm}$ : a) $3 D$ distribution, and b) $2 D$ distribution 
However, the simulations results appear to be very sensitive on the laser beam standard deviation, and for its value of 5 $\mathrm{mm}$, also, the maximum temperature $0.3 \mathrm{~s}$ after the start of interaction reaches $883 \mathrm{~K}$, as it can be seen in Fig. 11, which is much closer to the results obtained experimentally by the thermal imaging (a sample in this simulation was in dimensions $1 \times 1 \times 1 \mathrm{~cm})$

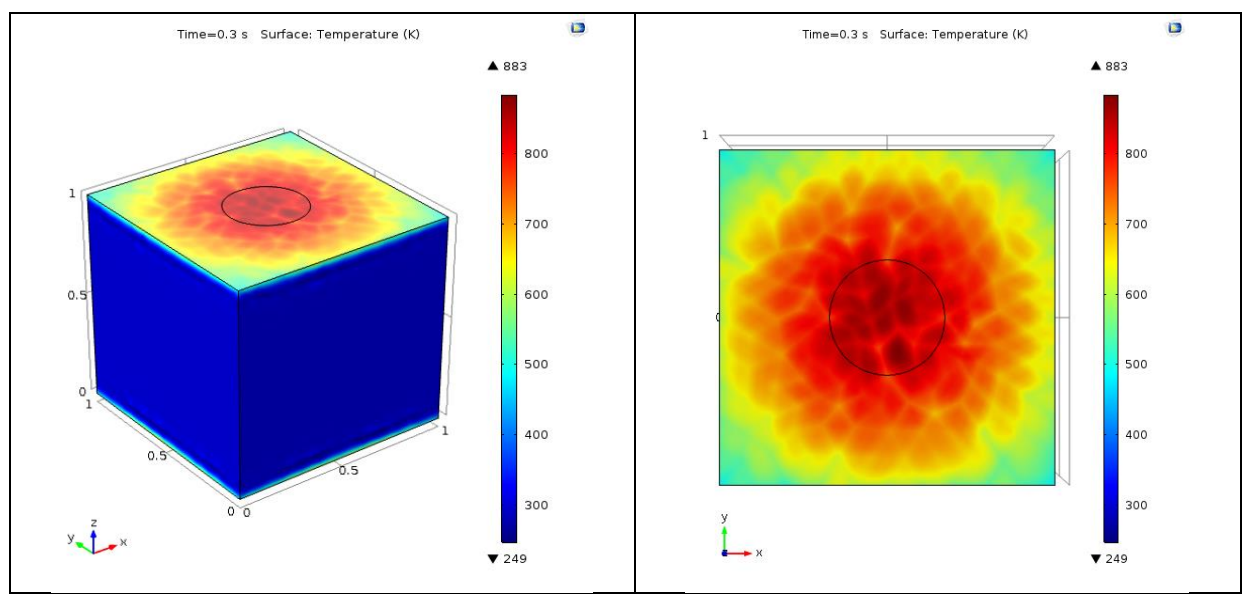

Fig. 11 Temperature distribution $0.3 \mathrm{~s}$ after the start of the $\mathrm{cw}-\mathrm{CO}_{2}$ laser-PMMA interaction simulated by the COMSOL Multiphysics 5.2 Program Package under the same working conditions as in Fig. 10, and the laser beam profile standard deviation of $5 \mathrm{~mm}$ :

a) $3 D$ distribution, and b) $2 D$ distribution, (same working conditions as in Figs. 6-8, $t=0.3 \mathrm{~s}$ )

If the dimensions of modeling sample change to $20 \times 10 \times 3 \mathrm{~cm}$, with the laser beam standard deviation of $5 \mathrm{~mm}$, and other parameters unchanged, the simulation pro- vide the temperature distribution that is pretty close to the one obtained by the thermal imaging, with maximum temperature of $552 \mathrm{~K}$, Fig. 12a), and b).

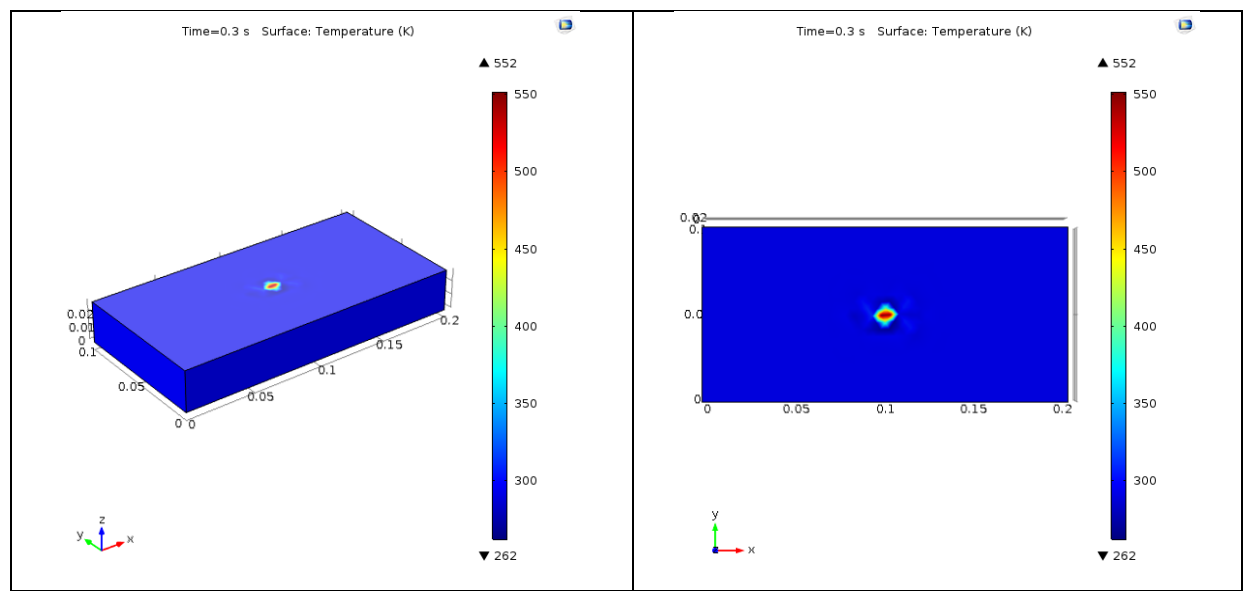

Fig. 12 Temperature distribution $0.3 \mathrm{~s}$ after the start of the $\mathrm{cw}-\mathrm{CO}_{2}$ laser-PMMA interaction simulated by the COMSOL Multiphysics 5.2 Program Package under the same working conditions as in Fig. 11, and the sample size of 20x10x3 cm: a) 3D distribution, and b) $2 D$ distribution. 
In case with the same geometry and dimension with standard deviation of $0.33 \mathrm{~mm}$, and with respect to the phase change (which include a latent energy), the ther-mal distribution slightly changes as it can be seen in Fig.13.

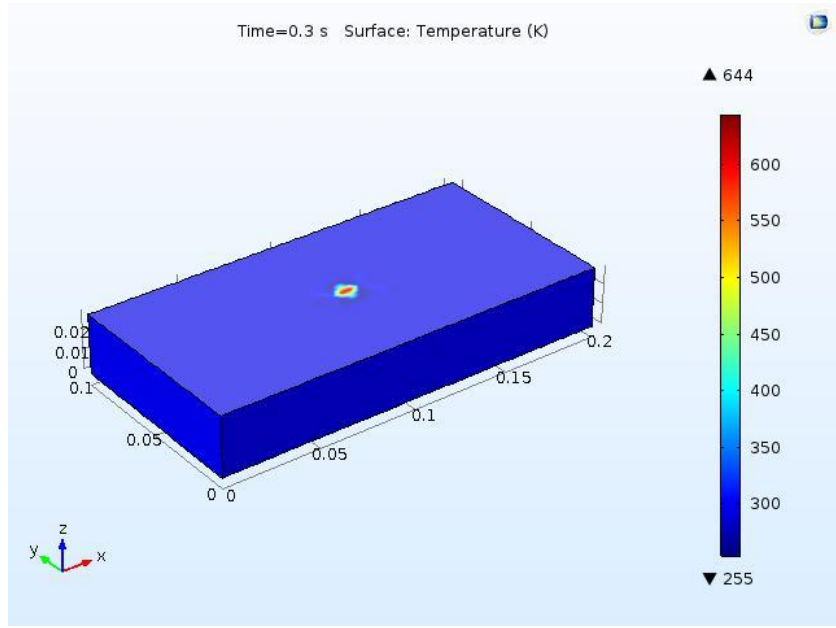

Fig. 13 Profiles of temperature distribution with the standard deviation of $0.33 \mathrm{~mm}$

It is possible to include a moving (translation) of beam into simulation. If a speed $(0.007 \mathrm{~m} / \mathrm{s})$ is put into a model, the lower temperature $(622 \mathrm{~K})$ is obtained as a result and that is presents in Fig.14.

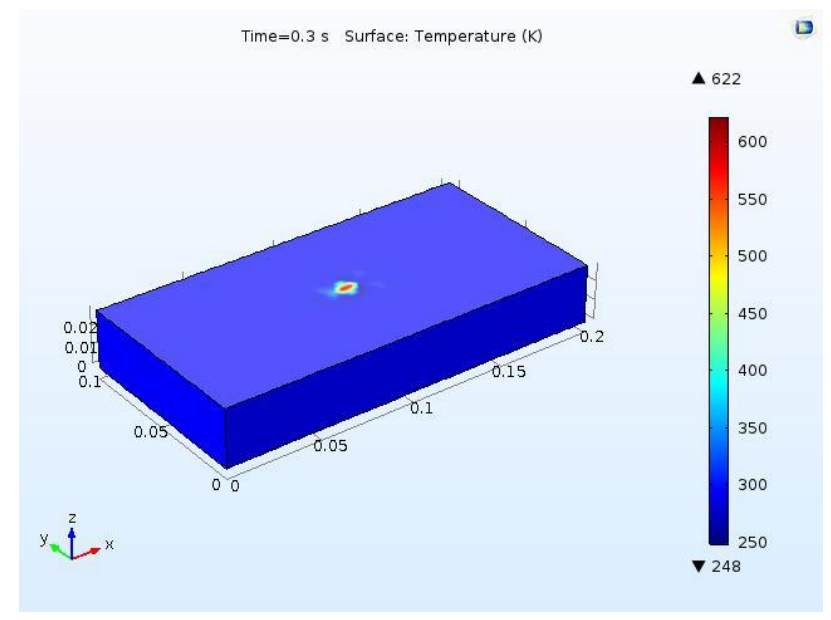

Fig. 14 Profile of temperature distribution with the standard deviation of $0.33 \mathrm{~mm}$ with a translational speed of $0.007 \mathrm{~m} / \mathrm{s}$

Here is underlained that the simulation could be provided with more realistic spot, it means that the standard deviation should be regarded to a real pulse, which diameter is pretty smaller and concentrated $\approx 0.3 \mathrm{~mm}$. 


\section{DISCUSSION AND CONCLUSION}

Laser methods of PMMA treatment are considered in numerous articles from various points of view: simulations, experiments with different types of laser devices, industrial applications, material processing for optical components, cutting and shaping of panels, tropheys, fiber applications, etc. [3-10, 19-27]. The part of the theory used in these descriptions is applicable also for the other transparent materials, composites, glassy and plastic materials.

During the experiments presented in this work, numerous specimens of different PMMA materials were cut using the cw$\mathrm{CO}_{2}$, and $\mathrm{Nd}^{3+}$ :YAG laser beams, under the same cutting conditions.

The attempts to decrease the surface roughness of processed material usually increase the manufacturing costs, but improves the performances of a component obtained by that way. From that reason, the surface roughness of PMMA samples after the laser cutting was measured and expressed in terms of the average roughness $R_{a}$. Under the used cutting conditions the largest $R_{a}$ of $0.52 \mu \mathrm{m}$ is obtained for sample $\mathrm{C} 1$, and the smallest $(0.3 \mu \mathrm{m})$ for sample $\mathrm{C} 2$ (Table 1). Such a large deviation of $R_{a}$ values can be explained by presence of different fillers \& pigments in various PMMA samples and some fluctuations of processing parameters observed during the cutting.

A characteristic feature observed for the PMMA laser cutting is the existence of a narrow LAZ zone, similar to amorphous structure, which is similar to those observed after the resistance, induction, or electron beam melting. In general, during the laser beam treatment of materials, a huge energy gradient of about $10^{8} \mathrm{~W} / \mathrm{cm}^{2}$ that is fundamentally different from the conditions during the mechanical machining.

However, the temperature distribution produced by the elion technics depends also on the material properties, and its simulation must be supported by the adequate material parameters and conducted using the appropriate thermodynamic and other theories that could provide the reliable predictions of absorbed energy, its conversion into heat, and subsequent heat redistribution.

Under the investigated working conditions, the maximum temperature of $775.1 \mathrm{~K}$ $\left(502^{\circ} \mathrm{C}\right)$ was provided by simulation, Fig. 8 , compared to $318.4^{\circ} \mathrm{C}$ experimentally recorded by the thermal imaging.

The maximum temperature values, obtained in provided monitoring and simulations, either using the thermal imaging or used program packages (COMSOL 3.5, 44.4 and 5.2), have shown some disagreements; it could be explained from the inadequate values of coefficient in thermodynamic equations for heat generation and its conduction. It means that the absorption/reflection coefficients of laser beam interaction with surface, also at presence of filler/pigment components and complex thermodynamic conditions, need more precise determinations.

\section{REFERENCES}

[1] S. Ristić, M. Srećković, The Implementation of Lasers in Rheological Investigation and Optimization of Holographic Interferogram, OPTO; Proc., pp. 186-193(1), 14-16 avr. 1992.

[2] Heat and Mass Transfer during Solidifications, Eds. B. Spalding, N. H. Afgan, Heat and Mass Transfer in Metallurgical Systems, Washington, Hemisphere Publ. Corp. 1981.

[3] Fundamentals of Fracture Mechanics and Structural Assessment Methods, Belgrade, Eds.L.M., MS, SS, Modern Approach to Control and Modes Structure Testing Methods, Faculty of Mechanical Eng., Belgrade, 2009, pp. 237261.

[4] P. Krstić, Multiphoton Ionization Processes in Strong Laser Fields, Ph.D. Thesis, City University of New York, 1981.

[5] A. Kovačević, M. Srećković, R. Gospavić, S. Ristić, P. Jovanić, Laser PMMA Interaction and Mechanical 
Stresses, Acta Physica Polonica, A., Vol.112, No.5, 2007, pp. 987-992, 981-986.

[6] M. Srećković, J. Ilić, M. Davidović, B. Đokić, Ž. Tomić, Z. Latinović, D. Družijanić, Laser Inter Action with Material-Theory, Experiments and Discrepancies, Acta Phys.Polonica A., Vol.116, No.4, pp. 618-621, 2009.

[7] M. Srećković, A. Kovačević, S. Bojanić, Lj. Vulićević, S. Ristić, V. Rajković, Damages Induced by Laser Beams in Organic Materials, Laser Phys., Vol.11, No.3, pp.336-342, 2001.

[8] M. Srećković, A. Kovačević, M. Davidović, M. Dinulović, M. Kutin, A. Milosavljević, B. Djokić: Heating Phenomena and Approaches for Active and Passive Materials, Kopaonik Serbia, SPIG 2006, Proccedings Book, pp. 243-247.

[9] I. Black, Laser Cutting of Perspex, J Mat. Science Letters Vol.17, 1998, 1531-1533.

[10] Mirkin, Physical Basis of Material Processing by Laser Beams, Mosque University, 1975 (in Russian)

[11] J. Krueger, S. Martin, H. Maedebach, L. Urech, T. Lippert, A. Wokaun,W., Kautek, Femto and Nanosecond Laser Treatment of Doped Laser Polymethylmetcrilate, Apl Surf.Scien., Vol. 247, 2005, pp.406-411.

[12] M. Srećković, Lj. Vulićević, S. Bojanić, V. Rajković, S. Ristić, Contribution to Prognosys of Laser treatment Efficiency for Different Materials, Journal of Optics, India, 27/1998/1, pp.19-31.

[13] A. Husein, Y. Nukman, A.M. Sifullah: Effect of Process Parameter in Laser Cutting of PMMA Sheet and ANFIS Modeling for Online Control, MATEC Web of Conferences 77, 10003, 2016.

[14] C. De Marco, S. M. Eaton, R. Suriano, S. Turri, M. Levi, R. Ramponi, G. Cerullo, R. Osellame: Surface Pro-perties of Femptosecond Laser Ablated PMMA, Appl. Mater. Interfaces, 2 (8), pp. 2377-2384, 2010.

[15] Z. Stević, M. Rajčić-Vujasinović, D. Antić, Thermal Imaging Application, Technical Faculty Bor, Bor 2008, pp. 55-127 (in Serbian)

[16] B. Simić, D. Knežević, M. Srećković, D. Nikolovski, Modern Problems of Thermovision, Tehnika, Elektrotehnika, Vol. 62, No. 2, pp. 272-284, 2013 (in Serbian)

[17] M. Bass Ed., Laser Material Processing, North Holland Amsterdam, 1983.

[18] M. Srećković, Lj. Vulićević, V. Rajković, Ž. Tomić, Guide of Laser Damages, Technical Faculty, Čačak, 2004.

[19] M. Srećković, A. Bugarinović, Ž. Tomić, A. Kovačević, V. Rajković, Laser Interaction with Material: Theory, Experiment and Reality, Regional Center for Talents, Belgrade II, Belgrade 2012, in Serbian, pp. 246-329.

[20] R. Gospavić, PhD Thesis, Faculty of Electrical Engineering, Belgrade, 2007.

[21] M. Speka, S. Mattei, M. Pilloz, M. Ilie, The Infrared Thermographys Control of the Laser Welding of Amorphous Polymer, NDT E International Vol. 41 (3), pp.178-183,2008.

[22] R. Ndeda, P. N. Kioni, J. N. Keraita, Effect of Laser Parameters on PMMA during Laser Micromachining, A FEMLAB Simulation, Proceedings of the 2011 Mechanical Engineering Conference on Sustainable Research and Innovation, Vol. 2, $5^{\text {th }}-6^{\text {th }}$ May 2011, pp. 49-53.

[23] M. Janićijević, M. Srećković, B. Kaluđerović, S. Bojanić, M. Dinulović, A. Kovačević, D. Družijanić, Characterization of Laser Beams Interaction with Carbon Materials, Laser Physics, IOP Publ. Vol. 23, 2013, 056002 (12pp) DOI:10.1088/1054-660X/23/5/ 056002 
[24] M. Janićijević, M. Srećković, B. Kaluđerović, M. Dinulović, Z. Karastojković, Z. Kovačević, P. Jovanić, Evaluation of Laser Beam Interaction with Carbon Based Material, Cicek Chem. Industry and Chem. Engineering, Quarterly, Chem. Ind. Chem. Eng. Q Vol. 21, pp.63-69, 2015.

[25] Z. Latinovic, M. Sreckovic, M. Janicijevic, J. Ilic, J. Radovanovic, Numerical Modeling of Thermal Effects on
Biological Tissue during LaserMaterial Interaction, Physics Script, Vol. 2014, T162, DOI: 10.1088/00318949/2014/T162/ 014041

[26] J. Weiner, P. T. Ho, Light-Matter Interaction, Vol.1, Fundamentals and Applications, John Wiley and Sons, Hoboken, New Jersay, 2003

[27] R. M. Wood, Laser Damage in Optical Material, Adam Hilger, 1986, Bristol. 